\title{
OPTIMIZATION OF PROCESS PARAMETERS FOR PRODUCTION OF ANTIMICROBIAL METABOLITES BY AN ENDOPHYTIC FUNGUS ASPERGILLUS SP. CPR5 ISOLATED FROM CALOTROPIS PROCERA ROOT.
}

\author{
SHIV KR. VERMA, MOTI LAL, MIRA DEBNATH (DAS)* \\ School of Biochemical Engineering, Indian Institute of Technology, Banaras Hindu University, Varanasi, Uttar Pradesh, India. \\ Email: m.debnath.bce@itbhu.ac.in
}

Received: 15 December 2016, Revised and Accepted: 18 January 2017

\begin{abstract}
Objective: To study the antimicrobial activity of crude ethyl acetate extract from endophytic fungus in Calotropis procera root.

Methods: Endophytic fungus was screened for production of antimicrobial metabolites. Fermentation was carried out in 500 ml Erlenmeyer flask. Disc diffusion method was used to test antimicrobial activity of crude extract using chloramphenicol sulfate and fluconazole as a positive control.

Results: A total of 14 endophytic fungi were isolated (CPR1-CPR14). Among these 14 isolates, CPR5 was found to show maximum antimicrobial activity, in compare to other isolates, against Gram-positive, Gram-negative bacteria and fungi. The antimicrobial activity was tested in opposition to Escherichia coli, Pseudomonas aeroginosa, Bacillus subtilis, Staphylococcus aureus, Ralstonia solanacearum, Xanthomonas oryzae, Penicillium chrysogenum, Candida albicans, Phoma exigua, Sclerotium rolfsii, and Sclerotinia scleratiourum. Minimum inhibitory concentration of crude extract against test microorganisms was determined. Fungus was identified as Aspergillus sp. production parameters (temperature, pH, carbon source, nitrogen source, and sodium chloride concentration) were optimized.
\end{abstract}

Conclusion: Crud extract produced by the isolated endophytic fungus could be an important source of broad-spectrum antimicrobial metabolites.

Keywords: Endophytic fungi, Antimicrobial metabolites, Process optimization, Calotropis procera, Inhibition zone.

(C) 2017 The Authors. Published by Innovare Academic Sciences Pvt Ltd. This is an open access article under the CC BY license (http://creativecommons. org/licenses/by/4. 0/) DOI: http://dx.doi.org/10.22159/ajpcr.2017.v10i4.16631

\section{INTRODUCTION}

Endophytes are the microbes that reside inside healthy plant tissues without showing any disease symptoms on the host [1]. This is a topographical term and includes bacteria, fungi, actinomycete, and algae, which spend their whole life or a period of life cycle in the healthy plant tissues without producing any disease or clinical symptoms [2]. Endophytic fungi that colonized inner plant tissues have been found to be associated with every plant species so far investigated. They are asymptomatic and often considered as mutualistic, benefiting the host by producing plant growth regulatory, antimicrobial, antiviral, and insecticidal substances [3]. It has been estimated that there may be as many as 1 million different fungal species on our planet $[4,5]$ The symbiosis between plant and endophyte was ascertained, namely, the former protects and feeds the latter which produces "in return" bioactive (plant growth regulatory, antibacterial, antifungal, antiviral, insecticidal, etc.) substances to enhance the growth and competitiveness of the host in nature [6,7]. Antioxidant property of metabolites from endophytic fungi has also been reported by some workers [8]. Endophytic fungi are ubiquitous in plant species, and they have also been reported to produce anticancer antiprotozoal and antimalarial substances. Some can produce similar or identical biologically active constituents as the host, such as taxol $[9,10]$. Endophytic fungi are typically identified through a comparison of morphological features. Typically, distinguishing between closely related or morphologically similar species is a complex task. The morphological characters of endophytic fungi can be a growth medium specific, and the cultural conditions can impact the sexual and vegetative compatibility of the fungi [11,12]. Antimicrobial compounds produced by endophytes may be involved in defense against pathogens [13]. In addition, these compounds may also reduce cell toxicity toward higher organisms because the plant itself serves as a natural selection system [14]. In our preliminary research, 14 endophytic fungi from different sections of root of Calotropis procera were isolated, and one isolate which belongs to Aspergillus niger sp. was isolated and was found to have potential for production of antimicrobial metabolites. Media composition (effect of various carbon sources, nitrogen sources, and yeast extract concentration) and culture condition $(\mathrm{pH}$ and incubation period temperature) were also studied to observe maximum antimicrobial activity.

C. procera is the famous Indian traditional medicinal plant, all the parts, namely; root, stem, leaf, and flowers of calotropis are in common use in indigenous system of medicine. The leaves of $C$. procera are also used to treat jaundice. Other compounds have been found to have bactericidal and vermicidal properties. The latex contains a photolytic enzyme called caloptropaine. An infusion of bark powder is used in the treatment and cure of leprosy and elephantiasis [15-18]. Therefore, the plant was selected as a source of endophytic microorganisms. However, the available literature has provided information on the isolation of endophytes from C. Procera, but a little information on study of optimization parameter for bioactive metabolites from the endophytes. Therefore, the purpose of the report was to isolate an endophyte from this host plant and optimization of production parameter for antimicrobial metabolite. Thus, this report describes a Aspergillus sp. isolate that produces bioactive metabolites.

\section{METHODS}

Plant sample collection

Root samples of $C$. procera were collected from agricultural field of Banaras Hindu University, Varanasi, Uttar Pradesh, India (25.5-N 82.9-E, elevation: $279 \mathrm{ft} / 85 \mathrm{~m}$ ). The plant was identified on the basis of external morphology characteristic features. A complete mature and healthy plant was rooted out from soil surface. The samples were collected in sterile polythene bags and brought to the laboratory in an 
icebox. Samples were preserved at $4^{\circ} \mathrm{C}$ in a refrigerator and processed for isolation of endophytic fungi immediately.

\section{Isolation and extraction of endophytic fungi}

Before applying any chemical treatment, roots were washed in running tap water for 10-12 minutes, to remove heavy load of soil particle and microbial concentration followed by washing with double distilled water. Samples were successively surface sterilized by the method given by Petrini et al. [19] and Schulz et al. [20]. Sample fragments were successively surface sterilized by immersing in $70 \%(\mathrm{v} / \mathrm{v})$ ethanol for 1-3 minutes followed by washing with $5 \%$ aqueous solution of sodium hypochlorite for 5 minutes and again in $70 \%$ ethanol for 30 seconds. After being rinsed in sterile water for 3 times, the roots were cut into $1 \mathrm{~cm}$ length bars. The bars were longitudinally halved and incubated in Petri dishes containing potato dextrose agar (PDA) medium supplemented with chloramphenicol $(50 \mu \mathrm{g} / \mathrm{ml})$ and streptomycin sulfate $(250 \mu \mathrm{g} / \mathrm{ml})$ to suppress bacterial growth PDA medium at $28^{\circ} \mathrm{C}$ until the mycelia or colonies appeared around the segments.

\section{Identification and molecular characterization of the fungus}

Morphologically, fungus was studied using lactophenol cotton blue staining; isolate was identified at genus level based on mycelial morphology and for identification and characterization at molecular level, total DNA of the endophytic fungus isolate was extracted from fungal mycelia grown in PDA using PrepMAN Ultra Sample Preparation Reagent kit according to the manufacture's recommendation (Nucleopore). A pair of ITS primer IT1 (5'GTAGTCATATGCTTGTCTC 3') [Qiagen] and IT4 (5' CTTCCGTCAATTCCTTTAAG 3') was used to amplify the highly specific and conserved sequence for endophytic fungi [21]. Polymerase chain reaction (PCR) was carried out in a programmable thermal controller (Biorad). In PCR reaction mixture of a total volume of $2.5 \mu \mathrm{l}$, it contained $10 \mu$ l template DNA, $14.5 \mu$ PCR Master mix (PCR buffer, $4 \mathrm{mM}$ $\mathrm{MgCl}_{2}, 0.4 \mathrm{mM}$ of each dNTP, and $0.05 \mathrm{U} / \mu \mathrm{l}$ Taq polymerase) (Fermentas), $1 \mu \mathrm{l}$ of each primer (IS1 and IS4), and double distilled water to make up the volume. The amplification was performed for 34 cycles having preset program of 1 minute at $94^{\circ} \mathrm{C}, 1$ minute at $45^{\circ} \mathrm{C}$, and 2 minute at $72^{\circ} \mathrm{C}$. After the final cycle has been completed, the amplification was extended for 10 minute at $72^{\circ} \mathrm{C}$. The amplified DNA fragment (approximately $400 \mathrm{bp}$ ) was purified and was sequenced by Genetic Analyzer. The sequences were compared to rDNA-ITS gene sequences in the public database using the BlastN program (http://www.ncbi.nlm.nih.gov). The phylogenetic tree was produced using basic local alignment search tool (BLAST) pairwise alignments.

\section{Microorganisms tested and antimicrobial activity test}

Escherichia coli, Bacillussubtilis, Staphylococcusaureus, and Pseudomonas aeroginosa; and human pathogenic fungus, Candida albicans; and three plant pathogenic fungi Sclerotium rolfsii, Sclerotinia scleratiourum, and Penicillium sp., were used to test antimicrobial activity fungal extract. Disc diffusion method [22] was followed for all the microorganisms. The microbial suspensions of particular concentration $(O D=0.5)$ were evenly spread out with sterile glass spreader. Sterile paper discs (6 $\mathrm{mm}$ diameter) were placed in the center of each Petri plate and loaded with $15 \mu \mathrm{l}$ of crude extract and sealed with Parafilm. Bacterial plates were incubated at $36 \pm 2^{\circ} \mathrm{C}$ for $24 \mathrm{hrs}$ and fungal plates at $27^{\circ} \mathrm{C}$ for 48 hrs, respectively. The zone of inhibition was recorded after the specified incubation period. Three replicates of each experiment were maintained to avoid error in measurements.

\section{Cultivation and metabolite extraction}

A piece of agar plug $\left(0.3 \times 0.3 \mathrm{~cm}^{2}\right)$ containing fungal hyphae was transferred to each $250 \mathrm{~mL}$ Erlenmeyer flask containing $100 \mathrm{ml}$ sterile medium (yeast extract $3.0 \mathrm{~g} / \mathrm{l}$; malt extract $3.0 \mathrm{~g} / \mathrm{l}$; peptone $0 \mathrm{~g} / \mathrm{l}$; and glucose $10 \mathrm{~g} / \mathrm{l}$ ) and incubated on a Rotary Shaker at $140 \mathrm{rpm}$ and at $28 \pm 2^{\circ} \mathrm{C}$ for $8-10$ days. A total of 50 flasks were used to collect required volume of broth. Thereafter, a total of $5 \mathrm{l}$ fermentation broth was collected for each isolate (CPR1-CPR18). The filtrate was extracted three times with an equal volume of ethyl acetate (EtOAc), and the EtOAc layer was collected. The frozen mycelia were crushed completely and extracted three times repeatedly by ultrasonic treatment and with
EtOAc. Both the broth extract mycelial extract were combined and evaporated in a Rotary Vacuum Dryer till solid residue remained. Crude extract was evaporated to make solid residue, and the stock solution was prepared in the concentration of dimethyl sulfoxide

\section{Antimicrobial activity of fungal extracts}

Antimicrobial activity of fungal extracts was tested using paper disc diffusion method. $15 \mu \mathrm{l}$ of crude extract from stock solution $(1 \mathrm{mg} / \mathrm{ml})$ was added into sterile filter paper disc ( $6 \mathrm{~mm}$ diameter). Discs with the crude extract were placed over Petri plates inoculated with test organisms. All the plates were incubated at $37^{\circ} \mathrm{C}$ for $24 \mathrm{hrs}$. The zone of inhibition was measured and expressed in millimeter.

\section{Incubation period for antimicrobial agent production}

The cultures were incubated for 8-12 days having optimized culture conditions, and optimum period for antimicrobial metabolite production was determined.

\section{Medium optimization}

Parameter optimization is one of the key parts of microbial production system. Optimum culture condition imparts suitable physiological and physical conditions that would affect the antimicrobial agent production of the selected strain. $1 \%(\mathrm{w} / \mathrm{v})$ of different carbon sources (sucrose, maltose starch, lactose, and fructose) including glucose was used in the experiments for antimicrobial agent production by CPR5. The effect of addition of different inorganic and organic nitrogen sources at equimolar concentration was studied to enhance the antimicrobial agent production by CPR5. Temperature variation was also studied as one of the parameters for antimicrobial agent production, a temperature range of $15-40^{\circ} \mathrm{C}$ was studied for maximum level of antimicrobial agent production. Different concentrations of yeast extract were added to test their effect on the antimicrobial agent production. $\mathrm{pH}$ is also a very important in parameter because inappropriate $\mathrm{pH}$ may change overall physiological and physical environment of microorganisms resulting in decrease in the production of desired product; therefore, we have also optimized $\mathrm{pH}$ in the range of 3.0-9.0 for maximum metabolite production.

\section{Standardization of biomass production}

The biomass accumulation and secondary metabolite production were recorded. Biomass accumulation was determined by drying the mycelial mat at $70^{\circ} \mathrm{C}$ until a constant weight was obtained and expressed as $\mathrm{mg} / \mathrm{ml}$.

\section{RESULTS AND DISCUSSION}

\section{Morphological and molecular identification of fungal isolate}

Eighteen endophytic fungal isolates have been isolated from $C$. procera plant and tested for antimicrobial activity, and among the 18 isolates, only one strain, which produced the wide-spectrum antibacterial substances with highest efficiency, was selected for morphological and molecular identification.

The growth of mycelial colonies found to be opaque and almost circular when grown on PDA at $34^{\circ} \mathrm{C}$ for 4 days. Representative image of endophytic fungal mycelia ( $\times 40$ inverted microscope) was obtained in the laboratory as image taken from 1-week old liquid culture it clearly shown that dense mycelia are intermingled with each other (Fig. 1).

The 18S rRNA sequencing (Fig. 2) followed by BLAST and SeqMatch analysis was used for molecular conformation endophytic isolate [23]. The 18S rRNA sequence was submitted to the DNA Data Bank of Japan and assigned an accession number (LC062385).

The 18S rRNA gene sequence (Fig. 2) was used to build a phylogenetic tree by performing automated BLASTN searches, to determine the closest type strain to the isolate under investigation. The percentage of identity was found to be $96 \%$. Phylogenetic tree analysis indicated that $18 \mathrm{~S}$ ribosome RNA sequence of CPR-5 strain was closely related to $A$. niger species (Fig. 2). The phylogenetic tree suggested that the 
local isolated strain is definitely a member of the genus Aspergillus and formed a common phylogenetic lineage that could be equated with a novel local species. From the results of inhibition zone, it is observed that the metabolite is a broad-spectrum antimicrobial agent, it inhibits the growth of both Gram-positive and Gram-negative bacteria. $1 \mathrm{mg} / \mathrm{ml}$ of crude metabolite was used in the experiment.

Maximum zone of inhibition was recorded against Staphylococcus hyicus $(21 \mathrm{~mm})$ followed by E. coli $(20 \mathrm{~mm})$. Equal zone of inhibition (18 mm) was observed for Vibrio sp. and Bacillus sp. The Inhibition

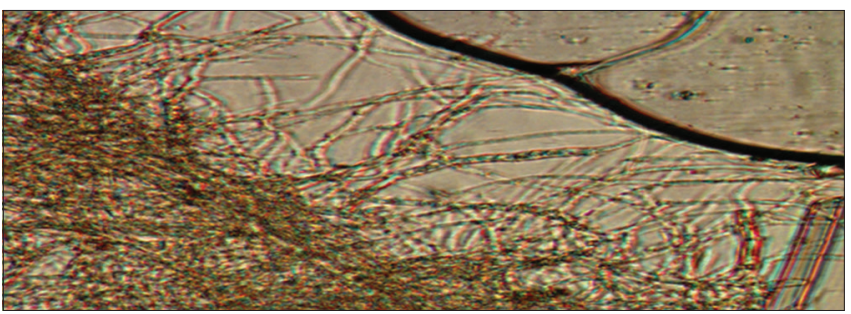

Fig. 1: Representative image of endophytic fungal mycelia ( $\times 40$ inverted microscope) zones against Pseudomonas sp. and S. Typhi was $16.02(\mathrm{~mm})$ and 17.02 $(\mathrm{mm})$, respectively (Fig. 3 ).

The antibacterial activity of bioactive compound produced by isolates CPR5 is comparable with chloramphenicol as a standard antibiotic (Table 1). Similarly, when antifungal activity was tested, it was observed that equal zone of inhibition $(18 \mathrm{~mm})$ was observed for Penicillium chrysogenum and $S$. rolfsii. Minimum zone of inhibition (16 $\mathrm{mm}$ ) was recorded for C. tropicalis. Zone of inhibition of 18 and $17 \mathrm{~mm}$ was observed for S. scleratiourum and Phoma exigua. Maximum zone of inhibition was recorded for $C$. albicans (Table 1) [24]. These observations were obtained from crude metabolites, and the results compared with fluconazole as a standard. From Table 1, it is clear that the metabolite from this isolate could be a promising source of antifungal agents.

\section{Media optimization}

The experiment was carried out to study the optimization parameter of culture condition to maximize the production of antimicrobial agent. In our present study, we tested various carbon sources at the concentration of $1 \%(\mathrm{w} / \mathrm{v})$ and of all the carbon sources added in the production medium inoculated with CPR5 isolate.

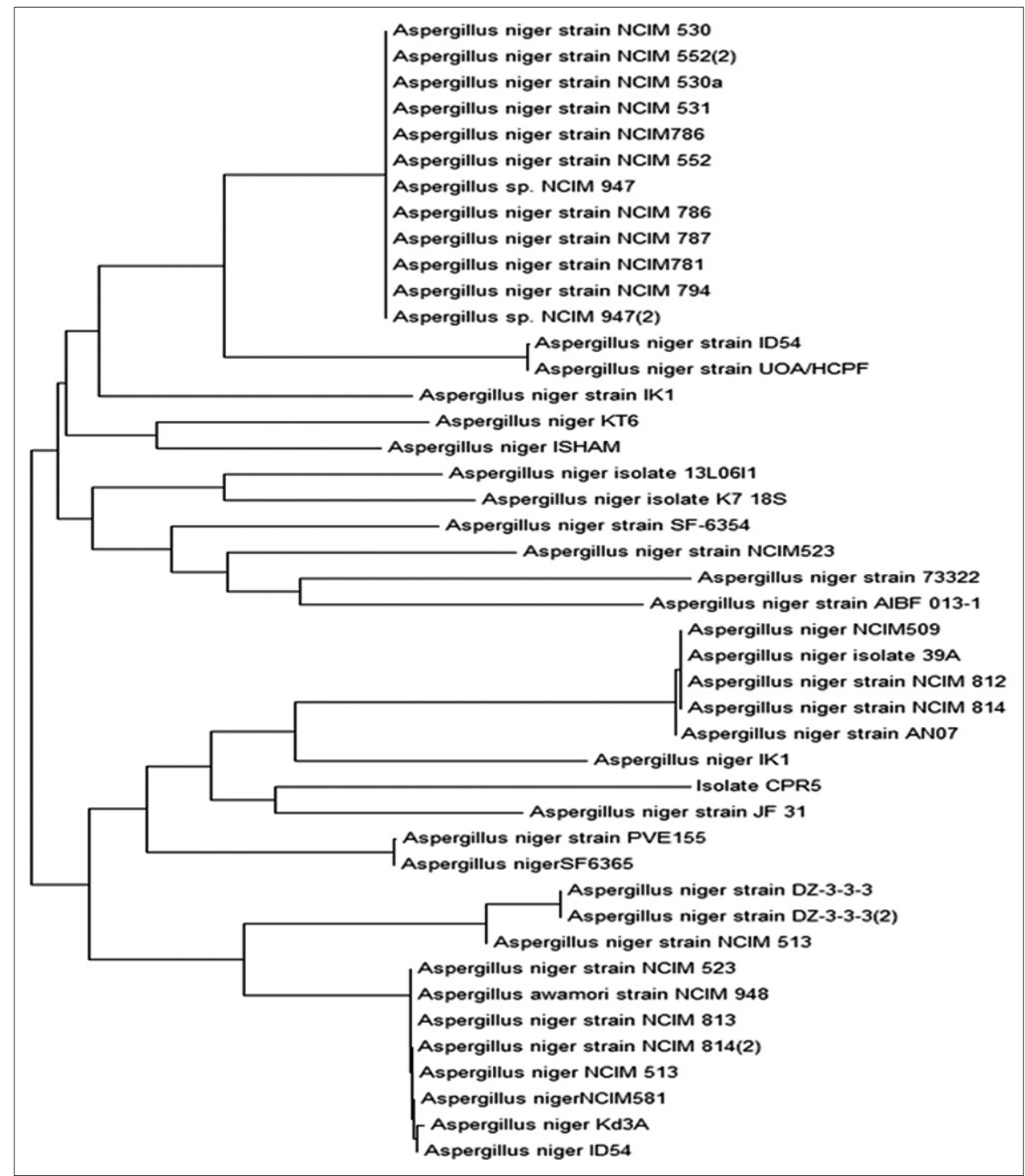

Fig. 2: Phylogenic tree based on $18 \mathrm{~S}$ rRNA sequence showing the relationship between fungal endophytic isolate from Calotropis procera (isolates R5) and reference strains, the evolutionary history was inferred using the UPGMA method 
Starch supported the highest level of antimicrobial metabolite followed by the medium supplemented with glucose and lactose, and low activity was observed with culture media supplemented with fructose maltose and galactose (Fig. 4). Addition of glucose resulted the highest growth of the fungus, but significantly in many fermentation processes, higher concentration of glucose has a suppressive effect on the production of bioactive metabolites [22]. All cultures were incubated for 8-9 days.

Various yeast extract concentrations were tested $(0.5-4.5 \mathrm{~g} / \mathrm{l})$ to see the effect on growth, and secondary metabolite production among the various concentration tested, yeast extract of $3 \mathrm{~g} / \mathrm{l}$ showed remarkable results followed by $3.5 \mathrm{~g} / \mathrm{l}$ and $2.5 \mathrm{~g} / \mathrm{l}$ concentrations (Fig. 5). A similar result was reported in literature $[25,26]$. The incubation temperature directly affects the overall growth and development pattern of the organism, and subsequently, the synthesis of various metabolites. Production levels of bioactive antibacterial compounds were observed at different temperatures such as $15^{\circ} \mathrm{C}, 20^{\circ} \mathrm{C}, 25^{\circ} \mathrm{C}, 30^{\circ} \mathrm{C}, 35^{\circ} \mathrm{C}$, and $40^{\circ} \mathrm{C}$.

Maximum growth and bioactive metabolite production by isolate CPR5 were recorded at incubation temperature $25^{\circ} \mathrm{C}( \pm 2)$, and it was followed by $30^{\circ} \mathrm{C}$ and $35^{\circ} \mathrm{C}$, respectively (Fig. 6). Similar results were reported in literature [27-29].

Table 1: Antifungal activity (inhibition zone) of the crude ethyl acetate extracts of isolate CPR5

\begin{tabular}{lll}
\hline \multirow{2}{*}{ Test fungi } & \multicolumn{2}{l}{ Zone of inhibition $\mathbf{( m m )}$} \\
\cline { 2 - 3 } & $\begin{array}{ll}\text { Culture filtrate } \\
(\mathbf{1} \mathbf{~} \mathbf{m} / \mathbf{m l})\end{array}$ & Fluconazole $\mathbf{( 1 ~} \mathbf{~ g} / \mathbf{m l})$ \\
\hline P. chrysogenum & $19 \pm 0.2$ & $28 \pm 0.2$ \\
P. exigua & $17 \pm 0.2$ & $23 \pm 0.2$ \\
S. rolfsii & $19 \pm 0.2$ & $26 \pm 0.2$ \\
S. scleratiourum & $18 \pm 0.2$ & $25 \pm 0.2$ \\
C. albicans & $19.5 \pm 0.2$ & $24 \pm 0.2$ \\
C. tropicalis & $16 \pm 0.2$ & $26 \pm 0.2$ \\
\hline
\end{tabular}

P. chrysogenum: Penicillium chrysogenum, P. exigua: Phoma exigua,

S. rolfsii: Sclerotium rolfsii, S. scleratiourum: Sclerotinia scleratiourum,

C. albicans: Candida albicans, C. tropicalis: Candida tropicalis

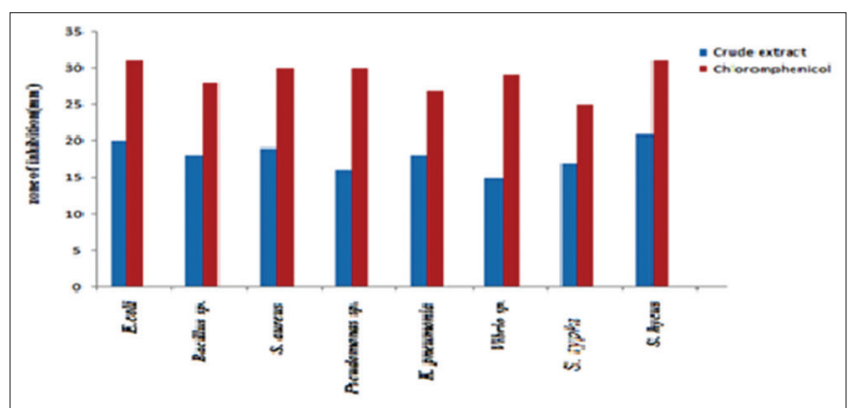

Fig. 3: Antibacterial activity (inhibition zone) of the crude ethyl acetate extracts of Isolate CPR5

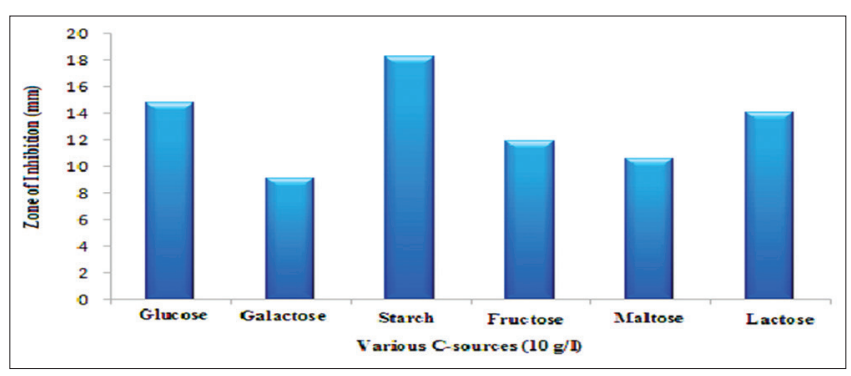

Fig. 4: Effect of various carbon sources on antimicrobial agent production
When effect of $\mathrm{NaCl}$ concentration was tested to see the effect of cell biomass production and bioactive metabolite production, it was observed that $\mathrm{NaCl}$ concentration at 3\%, 3.5\%, and $4 \%$ showed noticeable increase in both cell biomass and bioactive metabolite production and $3.5 \%$ of $\mathrm{NaCl}$ showed maximum observable values in biomass production (3.91 g/l) (Fig. 7).

Similar reports were given by Hansen [30] and Sailer et al. [31]. Initial pH 5.5 of the medium was observed to be optimal for growth and bioactive metabolites production by CPR5 (Fig. 8). Although initial pH 7.0 also supported biomass production and bioactive metabolite production, lower yield was observed. No growth was observed at pH 3, 4 and pH 9, 11 .

Vahidi et al. [32] reported that highest production of biomass by El-Wahid et al. 2011. was at $\mathrm{pH} 8$, whereas maximum toxic metabolite was produced at the $\mathrm{pH}$ 5. The $\mathrm{pH}$ of culture media is one of the very important determining parameters for the metabolism and hence for the biosynthesis of secondary metabolites. Permeability characteristics of the cell wall and membrane are also related to the cell environment $\mathrm{pH}$ value and thus have got the effect on either ion uptake or loss to the nutrient medium [33].

Incubation period was also observed for maximum bioactive metabolite production, and it was noticed that the cultures which were incubated for 8-9 days showed maximum bioactive metabolite production in comparison to other incubation period (Fig. 9).

Effect of various nitrogen sources was also studied. Equimolar concentration $(2 \%, \mathrm{w} / \mathrm{v})$ and various nitrogen sources $\left(\mathrm{NaNO}_{3}, \mathrm{KNO}_{3}\right.$,

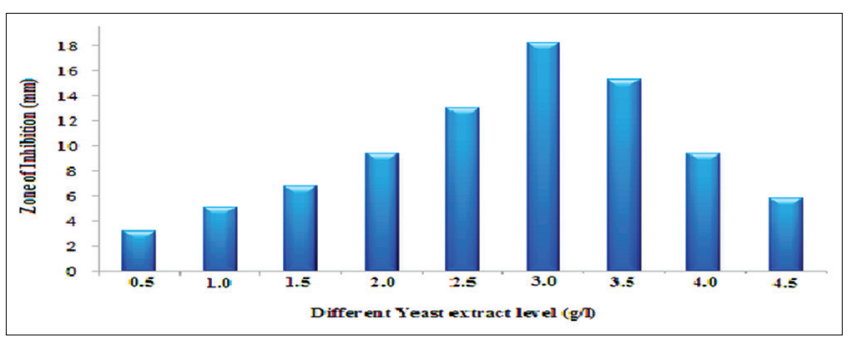

Fig. 5: Effect of yeast extracts concentration on antimicrobial agent production

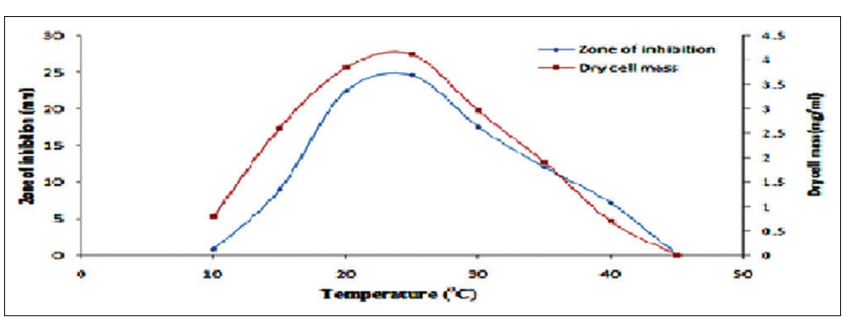

Fig. 6: Effect of temperature on production of antimicrobial metabolite

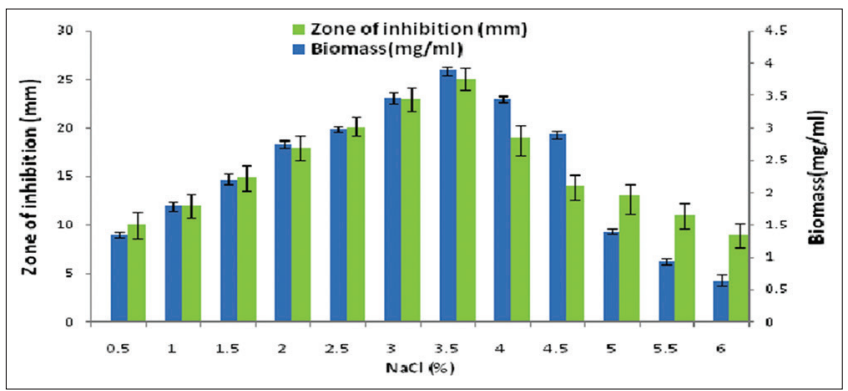

Fig. 7: Effect of various concentrations of $\mathrm{NaCl}$ on production of antimicrobial metabolite 
yeast extract, peptone, ammonium chloride, and ammonium sulfate) were added in the production medium, and after desired incubation period, it was observed that Yeast extract supported maximum biomass production $(4.2 \mathrm{~g} / \mathrm{l})$ followed by potassium nitrate $(3.94 \mathrm{~g} / \mathrm{l})$ was observed as the best nitrogen source for enhanced production of antimicrobial agent (Fig. 10). The requirement of nitrogen source generally differs from one microorganism to another. In case of most microorganisms, both inorganic and organic nitrogen source are metabolized to produce protein nucleic acid and various cell components. However, it has also been observed that some carbon and nitrogen sources have inhibitory effect of antimicrobial agent production. This negative result may be due to acid accumulation resulting in $\mathrm{pH}$ imbalance and oxygen depletion due to sugar catabolic repression.

Maximum antimicrobial agent was produced in starch medium followed glucose, by the isolate. In contrast, low activity was observed with maltose, lactose with least activity was shown by galactose, these carbon sources may affect metabolic pathway of primary and secondary metabolite production. It has been reported that generally addition of glucose enhances the metabolite production, but its significance in many fermentation processes decreases because at higher concentration, it has inhibitory effect.

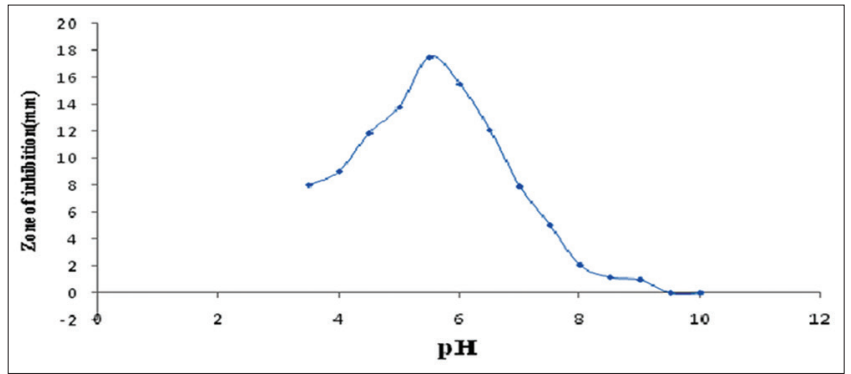

Fig. 8: Effect of initial pH on antimicrobial agent production

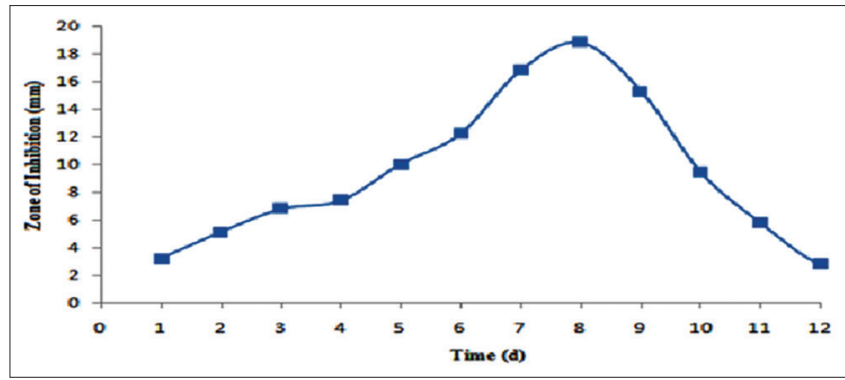

Fig. 9: Effect of incubation period on antimicrobial agent production

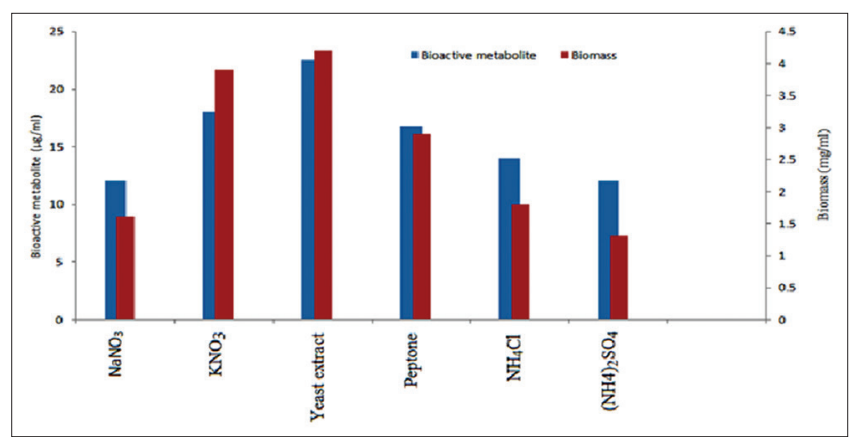

Fig. 10: Effect of nitrogen sources on antimicrobial agent production

\section{CONCLUSIONS}

From the above study, it was observed that various parameters such as temperature, incubation period, media composition, concentration of carbon sources, nitrogen sources, salt concentration, and $\mathrm{pH}$ affect the growth and production of metabolites from endophytic fungi A. niger sp. isolated from the plant $C$. procera. Medium composition prominently affects the growth and production of metabolites, and it also concludes that the isolate CPR5 is a potential source for bioactive metabolite production. The endophytes of medicinal plants provide a good source for compounds of biological activity, and endophytes are an untapped reservoir of potentially novel effective drugs. It can be concluded that the antibacterial activity of endophytic fungi is varied from species to species. Further isolation of bioactive compounds from the isolate reported in this study could work as a lead molecule in pharmaceutical industry.

\section{ACKNOWLEDGMENT}

This research work was funded by School of Biochemical Engineering, Indian Institute of Technology, BHU, Varanasi.

\section{REFERENCES}

1. Petrini O, Stone J, Carroll FE. Endophytic fungi in evergreen shrubs in Western Oregon: A prelimenary study. Can J Bot 1982;60(6):789-96.

2. Gond SK, Mishra A, Sharma VK, Verma SK, Kharwar RN, Kumar A. Diversity and antimicrobial activity of endophytic fungi isolated from nyctanthes arbor-tristis, a well-known medicinal plant of India. Mycoscience 2012;53(2):113-21.

3. Begum MM, Sariah M, Puteh AB, Abidin MA. Pathogenicity of Colletotrichum truncatum and ITS influence on soybean seed quality. Int J Agric Biol 2008;10(4):393-8.

4. Amirita A, Sindhu P, Swetha J, Vasanthi NS, Kannan KP. Enumeration of endophytic fungi from medicinal plants and screening of extracellular enzymes. World J Microbiol Biotechnol 2012;2(2):13-9.

5. Strobel G, Daisy B. Bioprospecting for microbial endophytes and their natural products. Microbiol Mol Biol Rev 2003;67(4):491-502.

6. Verma SK, Kumar A, Verma A, Debnath MD. Antimicrobial activity of endophytic fungal isolate in Argemone maxicana; A traditional Indian medicinal plant. Int J Innov Res Sci Eng Technol 2014;3(3):10151-62.

7. Hawksworth DL, Rossman AY. Where are all the undescribed fungi? Phytopathology 1997;87(9):888-91.

8. Preetha S, Srinivasan V. Antioxidant activities of ropinirole and pramipexole novel drugs used in treatment of parkinsonism: An in vitro approach. Asian J Pharm Clin Res 2016;9(3):105-7.

9. Stierle A, Strobel GA, Stierle D. Taxol and taxen production by Taxomyces andreanae an endophytic Fungus of Pacific yew. Science 1993;260(5105):214-6

10. Strobel G, Yang X, Sears J, Kramer R, Sidhu RS, Hess WM. Taxol from Pestalotiopsis microspora, an endophytic fungus of Taxus wallachiana. Microbiology 1996;142:435-40.

11. Kang JG, Shin SY, Kim MJ, Bajpai V, Maheshwari DK, Kang SC. Isolation and anti-fungal activities of 2-hydroxymethyl-chroman4-one Produced by Burkholderia sp. MSSP. J Antibiot (Tokyo) 2004;57(11):726-31.

12. Myers N, Mittermeier RA, Mittermeier CG, da Fonseca GA, Kent J. Biodiversity hotspots for conservation priorities. Nature 2000;403(6772):853-8

13. Gowrish A, Vagdevi HM, Rajashekar H. Phytochemical screening and antimicrobial activity of Leucas marrubioides desf. Root extracts. Int J Pharm Pharm Sci 2016;8(12):209-12.

14. Pharamat T, Palaga T, Piapukiew J, Anthony JS, Whalley AJS, Sihanonth P. Antimicrobial and anticancer activities of endophytic fungi from Mitrajyna javanica Koord and Val. Afr J Microbiol Res 2013;7(49):5565-72.

15. Sing AK, Raghubanshi AS, Sing JS. Medical ethnobotany of the tribals of Sonaghati of Sonbhadra district, Uttar Pradesh, India. J Ethnopharmacol 2002;81(1):31-41.

16. Parrotta JA. Healing Plants of Peninsular India. Wallingford, UK and New York: CAB International; 2001. p. 944.

17. Mossa JS. Pharmacological studies on aerial parts of Calotropis procera. Am J Chin Med 1991;19(3):223-31.

18. Anver S, Alam MM. Effect of latex seed dressing on interacting root-knot and reniform nematodes. Afro Asian J Nematol 1992;2(1):17-20. 
19. Petrini O, Sieber TN, Toti L, Viret O. Ecology, metabolite production, and substrate utilization in endophytic fungi. Nat Toxins 1992;1(3):185-96.

20. Schulz B, Wanke U, Draeger S, Aust HJ. Endophytes from herbaceous plants and shrubs: Effectiveness of surface sterilization methods. Mycol Res 1993;97(12):1447-50.

21. White TJ, Bruns TD, Lee SB, Taylor JW. Amplification and direct sequencing of fungal ribosomal RNA genes for phylogenetics. In: Innis MA, Gelfand DH, Sninshy JJ, White TD, editors. PCR Protocols: A Guide to Methods and Applications. London: Academic Press; 1990. p. 315-32.

22. Raahave D. Agar contact plate in evaluation of skin disinfection. Dan Med Bull 1974;20(6):204-8.

23. Saba Y, Vijay LM, Rajesh KM. Isolation and characterization of bioactive streptomyces from mangrove ecosystem of Machilipatnam, Krishna district, Andhra Pradesh. Asian J Pharm Clin Res 2016;9(3):258-63.

24. Arunodaya HS, Krishna V, Shashikumar R, Girish KK. Antibacterial and antioxidant activities of stem bark essential oil constituents of Litsea glutinosa C. B. Rob. Int J Pharm Pharm Sci 2016;8(12):258-64.

25. Hutter R. Design of culture media capable of provoking wide gene expression. In: Bullock JD, Nisbet LJ, Winstanley DJ, editors. Bioactive Microbial Products, Search and Discovery. London: Academic Press; 1982. p. 37-50.

26. Radu S, Kqueen CY. Preliminary screening of endophytic fungi from medicinal plants in Malayasia for antimicrobial and antitumour activity.
Malays J Med Sci 2002;9(2):23-33

27. Lethimaki J, Moisander P, Sivonen K, Kononen K. Growth, nitrogen fixation and nodularin production by two Baltic Sea cyenobacteria. Appl Environ Microbiol 1997;63(5):1647-54

28. Moita C, Feio SS, Nunes L, Joa M, Curto M, Roseiro JC. Optimisation of physical factors on the production of active metabolites by Bacillus subtilis 355 against wood surface contaminant fungi. Int Biodeterior Biodegradation 2005;55(4):261-9.

29. Digrak M, Eluk SZ. Determination of some fungal metabolite as influenced by temperature, time, $\mathrm{pH}$ and sugars by bioassay method. Turk J Biol 2001;25:197-203.

30. Hansen $\mathrm{OH}$. Ecology, physiology, and biochemistry of blue-green algae. Annu Rev Microbiol 1968;22:47-57.

31. Sailer M, Helms GL, Henkel T, Niemczura WP, Stiles ME, Vederas JC. $15 \mathrm{~N}$-and 13C-labeled media from Anabaena sp. For universal isotopic labeling of bacteriocins: NMR resonance assignments of leucocin A from Leuconostoc gelidum and nisin A from Lactococcus lactis. Biochemistry 1993;32(1):310-8.

32. Vahidi H, Kobarfard F, Namjoyan F. Effect of cultivation conditions on growth and antifungal activity of Mycena leptocephala. Afr J Biotechnol 2004;3(11):606-9.

33. Gogoi DK, Boruah HP, Saikia R, Bora TC. Optimization of process parameters for improved production of bioactive metabolite by a novel endophytic fungus Fusarium sp. DF2 isolated from Taxus wallichiana. Microbiol Biotechnol 2008;24(1):79-87. 